TITLE:

\title{
Enhanced grain boundary embrittlement of an Fe grain boundary segregated by hydrogen $(\mathrm{H})$
}

$\operatorname{AUTHOR}(\mathrm{S})$ :

Yuasa, Motohiro; Amemiya, Takashi; Mabuchi, Mamoru

\section{CITATION:}

Yuasa, Motohiro ...[et al]. Enhanced grain boundary embrittlement of an Fe grain boundary segregated by hydrogen (H). Journal of Materials Research 2012, 27(12): 15891597

ISSUE DATE:

2012-06

URL:

http://hdl.handle.net/2433/157320

RIGHT:

(c) Materials Research Society 2012. 


\title{
Enhanced grain boundary embrittlement of an Fe grain boundary segregated by hydrogen $(\mathrm{H})$
}

\author{
Motohiro Yuasa, Takashi Amemiya, and Mamoru Mabuchi ${ }^{\text {a) }}$ \\ Department of Energy Science and Technology, Graduate School of Energy Science, Kyoto University, \\ Yoshidahonmachi, Sakyo-ku, Kyoto 606-8501, Japan
}

(Received 12 October 2011; accepted 21 March 2012)

\begin{abstract}
First-principles fully relaxed tensile and shear test simulations were performed on $\Sigma 3(111) /[1 \overline{1} 0]$ tilt Fe grain-boundaries (GBs) with and without hydrogen $(\mathrm{H})$ segregation, to investigate the mechanisms of GB embrittlement enhanced by $\mathrm{H}$ segregation. Premature fracture was found in the $\mathrm{H}$-segregated GB, compared with the clean GB, in the tensile test simulations. The $\mathrm{Fe}-\mathrm{H}$ bond showed covalent-like and ion-like characteristics. The covalent-like characteristics reinforced the $\mathrm{Fe}-\mathrm{Fe}$ bonds, but the ion-like characteristics weakened the $\mathrm{Fe}-\mathrm{Fe}$ bonds as a result of charge transfer. The effect of the latter increased with increasing strain, and prevailed over the former, resulting in GB embrittlement. In the shear test simulations, variation in the GB energy for the $\mathrm{H}$-segregated GB was almost the same as that for the clean GB. This is because bond-breaking and rebonding occur concurrently in GB shearing and the variations in charge transfer during shear straining are less than those during tensile straining.
\end{abstract}

\section{INTRODUCTION}

Grain-boundary (GB) embrittlement in metals is often enhanced by impurity segregation at the GBs. Hydrogen $(\mathrm{H})$-induced GB embrittlement is one of the most critical problems in GB embrittlement, and it is still under debate. ${ }^{1,2}$ McMahon showed that there are two types of $\mathrm{H}$-induced GB embrittlement of steels: one is related to a combination of $\mathrm{H}$ and other impurities segregated at the GBs and the other results from the presence of $\mathrm{H}$ atoms only. ${ }^{3} \mathrm{H}$ atoms dissolve in the GB and presence of only the $\mathrm{H}$ atoms causes GB embrittlement because iron hydrides are not formed except under the limited conditions of high pressure and temperature. ${ }^{4}$ In such a situation, the effects of impurities on GB embrittlement can be estimated using the Rice-Wang thermodynamics model, ${ }^{5}$ in which the GB embrittlement is enhanced by impurities when the segregation energy at the free surface is lower than that at the GB. H segregation reduces the surface energy more than it reduces the GB energy, ${ }^{6,7}$ which agrees with the observed enhancement of GB embrittlement by $\mathrm{H}$ segregation. Recently, Yamaguchi et al. ${ }^{8}$ investigated the "mobile" effect of $\mathrm{H}$ on GB embrittlement, based on the Rice-Wang thermodynamics model. Also, Farkas et al. ${ }^{9}$ showed by dynamic simulations of GB fracture of Fe that a crack proceeds without deflection to the inside of the grains in $\mathrm{H}$-segregated Fe GBs. Mechanisms of the enhanced embrittlement of Fe GBs by $\mathrm{H}$ segregation have been investigated from the viewpoint of electronic structure, and it

\footnotetext{
a)Address all correspondence to this author.

e-mail: mabuchi@energy.kyoto-u.ac.jp

DOI: $10.1557 /$ jmr.2012.111
}

has been demonstrated that a charge transfer mechanism is responsible for the $\mathrm{H}$-induced $\mathrm{GB}$ embrittlement of $\mathrm{Fe}^{6,10,11}$ The electron populations of $\mathrm{Fe}-\mathrm{Fe}$ bonds in the GB plane can be decreased by $60 \%$ by charge transfer, ${ }^{11}$ where the $4 s$ and $4 p$ electrons play a dominant role. ${ }^{10}$ The $\mathrm{H}-\mathrm{Fe}$ bonding is ion-like, ${ }^{6}$ indicating that the charge transfer is due to ion-like characteristics. Gesari et al. ${ }^{12}$ showed the restrained $\mathrm{H}$-induced embrittlement of $\Sigma 5(013)$ Fe GB by addition of carbon (C) or boron (B) because of a strong repulsive interaction of $\mathrm{C}-\mathrm{H}$ and $\mathrm{B}-\mathrm{H}$.

Recently, the variations in electronic structure during straining have been investigated using first-principles fully relaxed tensile tests to gain a deeper understanding of GB embrittlement enhanced by impurity segregation. ${ }^{13-17}$ In general, the mechanisms of GB embrittlement enhanced by impurity segregation can be classified into two types: one is the decohesion mechanism, ${ }^{18,19}$ for example, in which the metal-metal bond is weakened as a result of charge transfer, and the other is the bond mobility mechanism, ${ }^{20-22}$ for example, in which the mobility of atoms is limited by strong covalent bonding. The calculations by first-principles fully relaxed tensile tests revealed that the first bond-breaking occurs at the $\mathrm{Fe}-\mathrm{Fe}$ bond around the impurity atom due to the weakened $\mathrm{Fe}-\mathrm{Fe}$ bond in the decohesion mechanism, ${ }^{16}$ while in the bond mobility mechanism, it occurs at the $\mathrm{Fe}$-impurity bond, in spite of the high charge density of the Fe-impurity bond. ${ }^{17}$ In the present work, first-principles fully relaxed tensile tests are performed on $\mathrm{H}$-segregated $\Sigma 3(111) /[1 \overline{1} 0]$ tilt Fe GBs and the bond-breaking events are investigated from the viewpoint of variations in electronic structure during straining. Some studies have been performed on $\mathrm{H}$-segregated $\Sigma 3 \mathrm{Fe}$ GBs so far, ${ }^{6,8,10}$ but to the authors' knowledge, there are no other studies by 
first-principles fully relaxed tensile tests on $\mathrm{H}$-segregated $\Sigma 3$ Fe GBs. The present work by first-principles fully relaxed tensile tests reveals that the first bond-breaking site is not the $\mathrm{Fe}-\mathrm{Fe}$ bond closest to the $\mathrm{H}$ atom because of the variations in electronic structure during straining. This finding highlights the importance of dynamic variations during straining for GB embrittlement. In addition, in the present work, first-principles shear tests are performed on the same Fe GBs to investigate the effects of $\mathrm{H}$ segregation on GB shearing.

\section{COMPUTATIONAL METHOD}

Two body-centered cubic (bcc) Fe cells with a $\Sigma 3(111) /[1 \overline{1} 0]$ tilt GB were used: one was a cell without $\mathrm{H}$ segregation at the GB (clean GB model), and the other was a cell with $\mathrm{H}$ segregation at the $\mathrm{GB}(\mathrm{H}$-segregated GB model), where a $\mathrm{H}$ atom was located in an energetically stable interstitial site, ${ }^{6,8,10}$ as shown in Fig. 1. The GB energy of $\Sigma 3(111) /[1 \overline{1} 0]$ tilt $\mathrm{GB}$ is relatively high $\left(=1.74 \mathrm{~J} / \mathrm{m}^{2}\right)$, which is comparable with those of random boundaries. The initial cell size was $4.05 \AA \times 7.02 \AA \times 14.89 \AA$. Geometry optimization calculations were performed using the Cambridge Serial Total Energy Package (CASTEP) ${ }^{23,24}$ in which density functional theory ${ }^{24,25}$ was used with a plane-wave basis set to calculate the electronic properties of the solids from first-principles. The exchange-correlation interactions were treated using the spin-polarized ferromagnetic version of the generalized gradient approximation within the Perdew-Burke-Ernzerhof scheme. ${ }^{26}$ Ultrasoft pseudopotentials $^{27,28}$ represented in reciprocal space were used for all elements in the calculations. The cutoff energy for the plane- wave basis set was $300 \mathrm{eV}$. The Brillouin zone was sampled using a Monkhorst-Pack $6 \times 4 \times 2$ k-point mesh $^{29}$ and Gaussian smearing with a $0.1-\mathrm{eV}$ width. These simulation conditions were determined as stipulated in Ref. 8.

After the geometry optimization calculation, including cell optimization, a uniaxial tensile strain with an increment of $2 \%$ in the [111] direction, which was normal to the GB plane, was applied to the cells for the firstprinciples fully relaxed tensile tests. The lattice dimensions in the GB plane were fixed, neglecting Poisson's ratio to simplify the calculations. ${ }^{13-17}$ This step was repeated until GB fracture occurred. In each step, all atomic positions were optimized in accordance with Hellmann-Feynman forces until all the forces were less than $0.03 \mathrm{eV} / \AA$. In the present study, bond-breaking was determined from a rapid increase in bond length.

In the first-principles shear tests, shearing was simulated by shifting one grain with respect to the other, corresponding to the translation vectors of $1 / 20$ of the $[11 \overline{2}]$ direction of the cell, and then relaxing the structure without cell optimization. The atoms in two layers in the middle of each grain were fixed to their bulk positions during the geometry optimization, while all the other atoms were allowed to be relaxed under the same conditions as in the tensile tests. ${ }^{30,31}$

\section{RESULTS AND DISCUSSION}

Figure 2(a) shows the total energy of the unit cell as function of tensile strain for the clean GB and H-segregated GB models. The maximum energy was $15.5 \mathrm{eV}$ for the clean GB model and $11.2 \mathrm{eV}$ for the H-segregated GB model, respectively. Clearly, the fracture energy for tensile

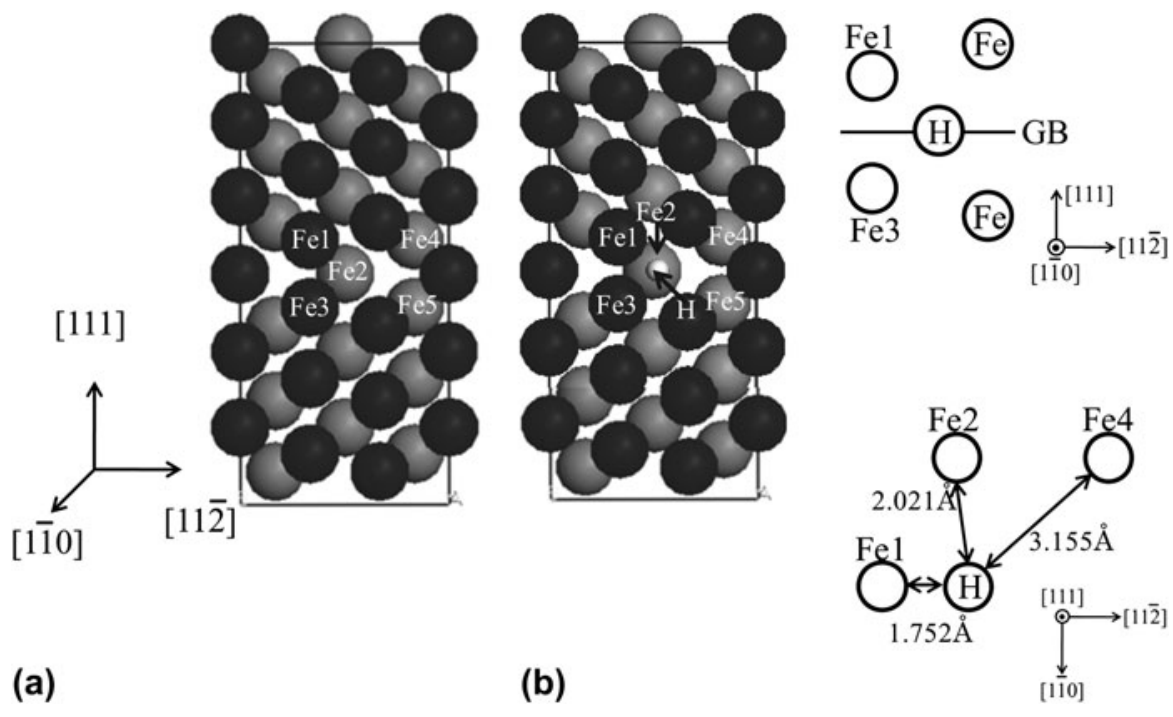

FIG. 1. Unit cell model of Fe with a $\Sigma 3(111) /[1 \overline{1} 0]$ tilt grain boundary. In the present study, two cells are used: one (a) is the cell without $H$ segregation at the grain boundary (clean GB model) and the other (b) is the cell with $\mathrm{H}$ segregation at the grain boundary (H-segregated GB model). The locations of atoms in the $\mathrm{H}$-segregated GB model are shown in detail on the right-hand side. The $\mathrm{Fe} 1-\mathrm{Fe} 3, \mathrm{Fe} 1(\mathrm{Fe} 3)-\mathrm{Fe} 2, \mathrm{Fe} 2-\mathrm{Fe} 4(\mathrm{Fe} 5)$, and $\mathrm{Fe} 4-\mathrm{Fe} 5$ bonds are the first-, second-, third-, and fourth-neighbor $\mathrm{Fe}-\mathrm{Fe}$ bonds, respectively, to the $\mathrm{H}$ atom in the $\mathrm{H}$-segregated GB model 
deformation was reduced by the $\mathrm{H}$ segregation. The stress-strain curves are shown in Fig. 2(b) for the clean GB and H-segregated GB models. The flow stress for the $\mathrm{H}$-segregated GB model was almost the same as that for the clean GB model up to $20 \%$ strain. In the clean GB model, the stress gradually increased with increasing strain until the strain reached $28 \%$, but the stress rapidly decreased at $28-30 \%$, and finally GB fracture occurred at $30 \%$. In the $\mathrm{H}$-segregated GB model, the stress rapidly decreased at

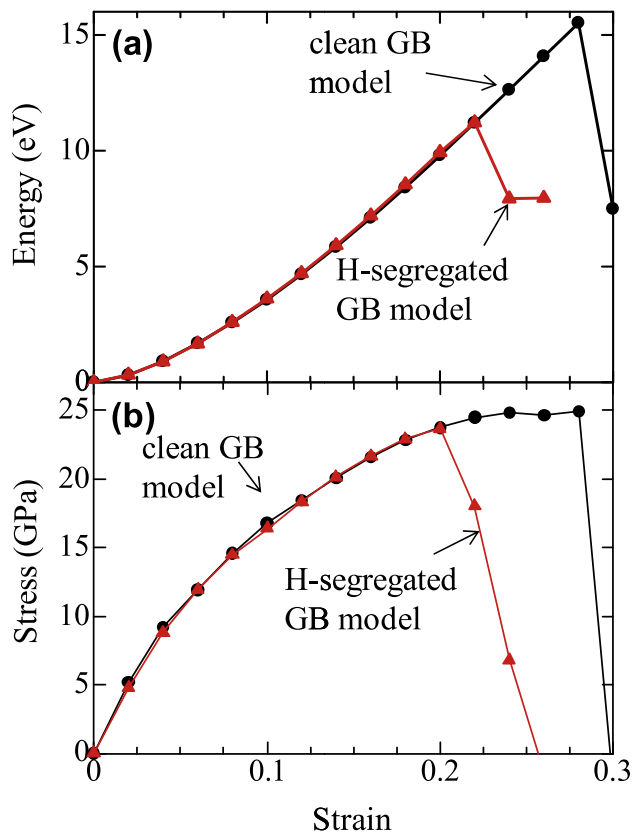

FIG. 2. Energy-strain curves (a) and Stress-strain curves (b) of the clean $\mathrm{GB}$ and $\mathrm{H}$-segregated GB models calculated from first-principles fully relaxed tensile tests.
$20-24 \%$, and finally GB fracture occurred at $26 \%$. Clearly, the $\mathrm{H}$ segregation enhanced the Fe GB embrittlement. The calculated $\Delta E_{\mathrm{GB}}-\Delta E_{\mathrm{SF}}$ for the $\mathrm{H}$ segregation in $\mathrm{Fe}$ was $0.39 \mathrm{eV} /$ atom, where $\Delta E_{\mathrm{GB}}$ is the segregation energy at the $\mathrm{GB}$ and $\Delta E_{\mathrm{SF}}$ is the segregation energy at the free surface. In this case, the difference between the segregation energies of the GB and the free surface was calculated in the static case, where the fracture surface was arbitrarily set between the two atomic layers in the GB. However, the difference in segregation energies may not be correctly estimated in the static case, because the configuration of the atoms is changed during straining. In the present work, the difference in segregation energies was calculated in the dynamic case, where the fracture surface was the surface after GB fracture, by the first-principles fully relaxed tensile test. As a result, $\Delta E_{\mathrm{GB}}-\Delta E_{\mathrm{SF}}$ for $\mathrm{H}$ segregation in $\mathrm{Fe}$ was $0.41 \mathrm{eV} /$ atom. Thus, the calculations in both the static and dynamic cases showed that $\mathrm{H}$ is a $\mathrm{GB}$ embrittler of $\mathrm{Fe}^{6}{ }^{6}$ The maximum stress was about $25 \mathrm{GPa}$ for the clean GB model, as shown in Fig. 2(b). This roughly agrees with the result of firstprinciples calculations by Yamaguchi. ${ }^{32}$ These calculated values are too large, when compared with experimental values. This is because inelastic deformation related to dislocations cannot be treated by the first-principles calculations.

The atomic configurations of $(1 \overline{1} 0)$ at $28 \%$ and $30 \%$ in the clean GB model and at $20 \%$ and $22 \%$ in the $\mathrm{H}$-segregated GB model are shown in Fig. 3. In the clean GB model, no bond-breaking occurred at $28 \%$, and the $\mathrm{Fe} 1-\mathrm{Fe} 2, \mathrm{Fe} 1-\mathrm{Fe} 3, \mathrm{Fe} 2-\mathrm{Fe} 4$, and $\mathrm{Fe} 4-\mathrm{Fe} 5$ bonds were broken at 28-30\%. In the $\mathrm{H}$-segregated GB model, however, the $\mathrm{Fe} 2-\mathrm{Fe} 4$ and $\mathrm{Fe} 2-\mathrm{Fe} 5$ bonds were broken at 20-22\%, and then the $\mathrm{Fe} 4-\mathrm{Fe} 5$ bond was broken. The Fe1-Fe3, $\mathrm{Fe} 1(\mathrm{Fe} 3)-\mathrm{Fe} 2, \mathrm{Fe} 2-\mathrm{Fe} 4(\mathrm{Fe} 5)$, and $\mathrm{Fe} 4-\mathrm{Fe} 5$ bonds were the

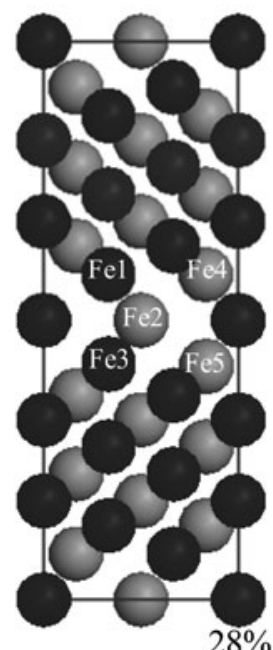

(a)

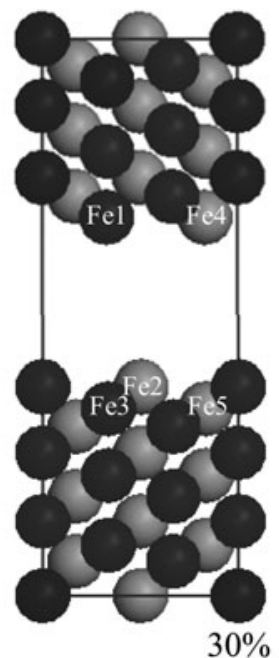

(b)

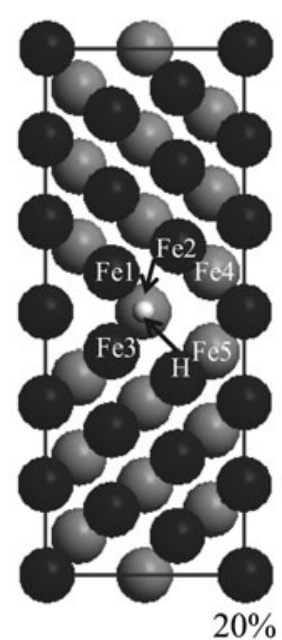

(c)

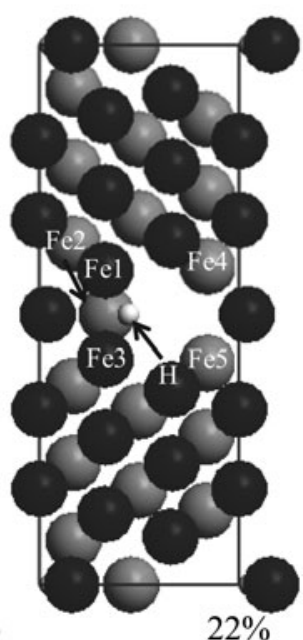

(d)

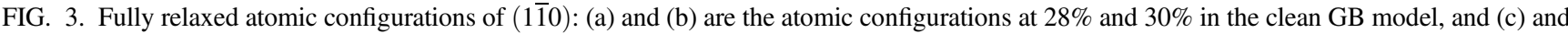
(d) are the atomic configurations at $20 \%$ and $22 \%$ in the $\mathrm{H}$-segregated GB model. Note that the site for the first bond-breaking in the H-segregated GB model is different from that in the clean GB model. 
first-, second-, third- and fourth-neighbor $\mathrm{Fe}-\mathrm{Fe}$ bonds, respectively, to the $\mathrm{H}$ atom in the $\mathrm{H}$-segregated GB model. Note that the third- and fourth-neighbor $\mathrm{Fe}-\mathrm{Fe}$ bonds to the $\mathrm{H}$ atom were broken more readily than the first- and secondneighbor $\mathrm{Fe}-\mathrm{Fe}$ bonds to the $\mathrm{H}$ atom in the $\mathrm{H}$-segregated GB model.

The variations in bond length of (a) the $\mathrm{Fe} 1-\mathrm{Fe} 2$ bond and (b) the $\mathrm{Fe} 2-\mathrm{Fe} 4$ bond as a function of strain are shown in Fig. 4. The bond length of $\mathrm{Fe} 1-\mathrm{Fe} 2$ prior to straining in the $\mathrm{H}$-segregated GB model was a little longer than that in the clean GB model, but the difference in the Fe1-Fe2 bond length decreased with increasing strain and became negligibly small at $10 \%$. In contrast, the bond length of $\mathrm{Fe} 2-\mathrm{Fe} 4$ prior to straining in the H-segregated GB model was a little longer than that in the clean GB model, and the difference in $\mathrm{Fe} 2-\mathrm{Fe} 4$ bond length increased with increasing strain. The variations in bond length during straining reflect variations in the strength of the atomic bonding. ${ }^{13-17}$ The $\mathrm{H}$ atom affected the $\mathrm{Fe} 2-\mathrm{Fe} 4$ bond more strongly than it affected the $\mathrm{Fe} 1-\mathrm{Fe} 2$ bond, although the $\mathrm{Fe} 2-\mathrm{Fe} 4$ bond was farther away from the $\mathrm{H}$ atom than the $\mathrm{Fe} 1-\mathrm{Fe} 2$ bond was.

The occupation numbers at $0 \%, 10 \%$, and $20 \%$ of the $\mathrm{Fe} 1, \mathrm{Fe} 2$, and $\mathrm{Fe} 4$ atoms were investigated to estimate the variations in charge transfer during straining. The results are listed in Table I. The descending order of total occupation numbers in the clean GB model prior to straining was $\mathrm{Fe} 1>\mathrm{Fe} 4>\mathrm{Fe} 2$. The total occupation number decreased with increasing strain for all $\mathrm{Fe}$ atoms, but the total occupation number order of $\mathrm{Fe} 1>\mathrm{Fe} 4>\mathrm{Fe} 2$ did not change during straining in the clean GB model. In the $\mathrm{H}$-segregated GB model, it was noted that the total oc-

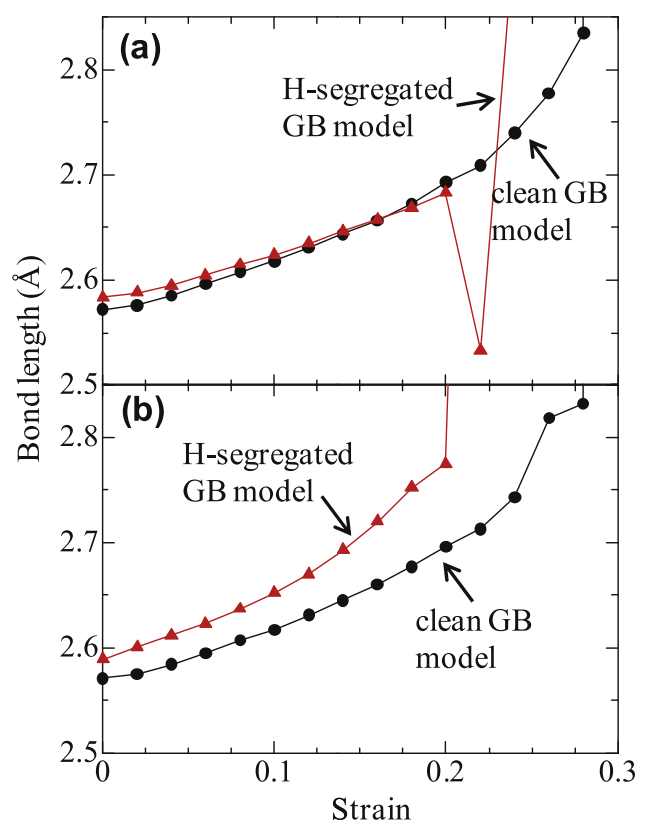

FIG. 4. Variations in lengths of the (a) $\mathrm{Fe} 1-\mathrm{Fe} 2$ bond and (b) $\mathrm{Fe} 2-\mathrm{Fe} 4$ bond as a function of strain in the clean $\mathrm{GB}$ and $\mathrm{H}$-segregated GB models. cupation number of the $\mathrm{Fe} 1$ atom was increased by straining; the $4 p$ electrons played an important role in the increased occupation number of $\mathrm{Fe} 1 .{ }^{10}$ In contrast, the total occupation numbers of $\mathrm{Fe} 2$ and $\mathrm{Fe} 4$ in the $\mathrm{H}$-segregated $\mathrm{GB}$ model were decreased by straining. The decreases in the total occupation numbers of $\mathrm{Fe} 2$ and $\mathrm{Fe} 4$ by straining in the $\mathrm{H}$-segregated GB model were larger than those in the clean GB model. The order of the total occupation numbers changed from $\mathrm{Fe} 4>\mathrm{Fe} 1>\mathrm{Fe} 2$ to $\mathrm{Fe} 1>\mathrm{Fe} 4>\mathrm{Fe} 2$ as a result of strain in the $\mathrm{H}$-segregated GB model. The changes in charge transfer during straining correspond to the fact that the $\mathrm{Fe} 2-\mathrm{Fe} 4$ and $\mathrm{Fe} 4-\mathrm{Fe} 5$ bonds were broken more readily than the $\mathrm{Fe} 1-\mathrm{Fe} 2$ and $\mathrm{Fe} 1-\mathrm{Fe} 3$ bonds in the $\mathrm{H}$-segregated GB model. Thus, the bond-breaking sites in the H-segregated GB model were affected by the changes in charge transfer during straining.

Figure 5 shows the charge-density distributions of (11) at $0 \%, 10 \%$, and $22 \%$. The $\mathrm{H}$ atom strongly bonded with the $\mathrm{Fe} 1$ and $\mathrm{Fe} 3$ atoms, and reinforced the $\mathrm{Fe} 1-\mathrm{Fe} 3$ bond in the $\mathrm{H}$-segregated GB model. The partial density of states (PDOS) of the $\mathrm{Fe} 1$ and $\mathrm{H}$ atoms at $0 \%, 10 \%$, and $20 \%$ in the H-segregated GB model are shown in Fig. 6. Hybridization peaks were observed at $-9 \mathrm{eV}$ to $-7 \mathrm{eV}$ in the $\mathrm{Fe} 1$ and $\mathrm{H}$ atoms. The $s$ electrons played a vital role in hybridization. ${ }^{10}$ The number of electrons related to the hybridization in $\mathrm{Fe} 1$ at $10 \%$ was larger than that at $0 \%$, and decreased little at $20 \%$. The covalent-like characteristics are probably responsible for the strong interaction of the $\mathrm{Fe} 1(\mathrm{Fe} 3)-\mathrm{H}$ bond. It is known that $\mathrm{P}$ segregation enhances

TABLE I. Occupation numbers for $3 d, 4 s$, and $4 p$ electrons of the Fe1, $\mathrm{Fe} 2$, and $\mathrm{Fe} 4$ atoms in the clean GB model and the H-segregated GB model. The electron occupation number is calculated by integrating the PDOS to the Fermi energy.

\begin{tabular}{lrcccc}
\hline \hline & & $3 d$ & $4 s$ & $4 p$ & Total \\
\hline Fe1 atom & & & & & \\
Clean GB model & $0 \%$ & 6.638 & 0.733 & 0.886 & 8.257 \\
& $10 \%$ & 6.617 & 0.649 & 0.972 & 8.237 \\
H-segregated GB model & $0 \%$ & 6.593 & 0.625 & 1.020 & 8.238 \\
& $10 \%$ & 6.663 & 0.711 & 0.851 & 8.226 \\
& $20 \%$ & 6.653 & 0.627 & 0.955 & 8.235 \\
Fe2 atom & & & 0.588 & 1.016 & 8.240 \\
Clean GB model & $0 \%$ & 6.528 & 0.597 & 1.000 & 8.126 \\
& $10 \%$ & 6.531 & 0.544 & 0.944 & 8.020 \\
H-segregated GB model & $0 \%$ & 6.521 & 0.503 & 0.819 & 7.843 \\
& $10 \%$ & 6.568 & 0.599 & 0.936 & 8.104 \\
& $20 \%$ & 6.551 & 0.513 & 0.843 & 7.909 \\
Fe4 atom & & & & & \\
Clean GB model & $0 \%$ & 6.637 & 0.723 & 0.886 & 8.247 \\
& $10 \%$ & 6.611 & 0.650 & 0.971 & 8.232 \\
& $20 \%$ & 6.585 & 0.627 & 1.024 & 8.235 \\
H-segregated GB model & $0 \%$ & 6.629 & 0.718 & 0.888 & 8.235 \\
& $10 \%$ & 6.602 & 0.640 & 0.980 & 8.222 \\
& $20 \%$ & 6.577 & 0.620 & 1.018 & 8.215 \\
\hline \hline
\end{tabular}



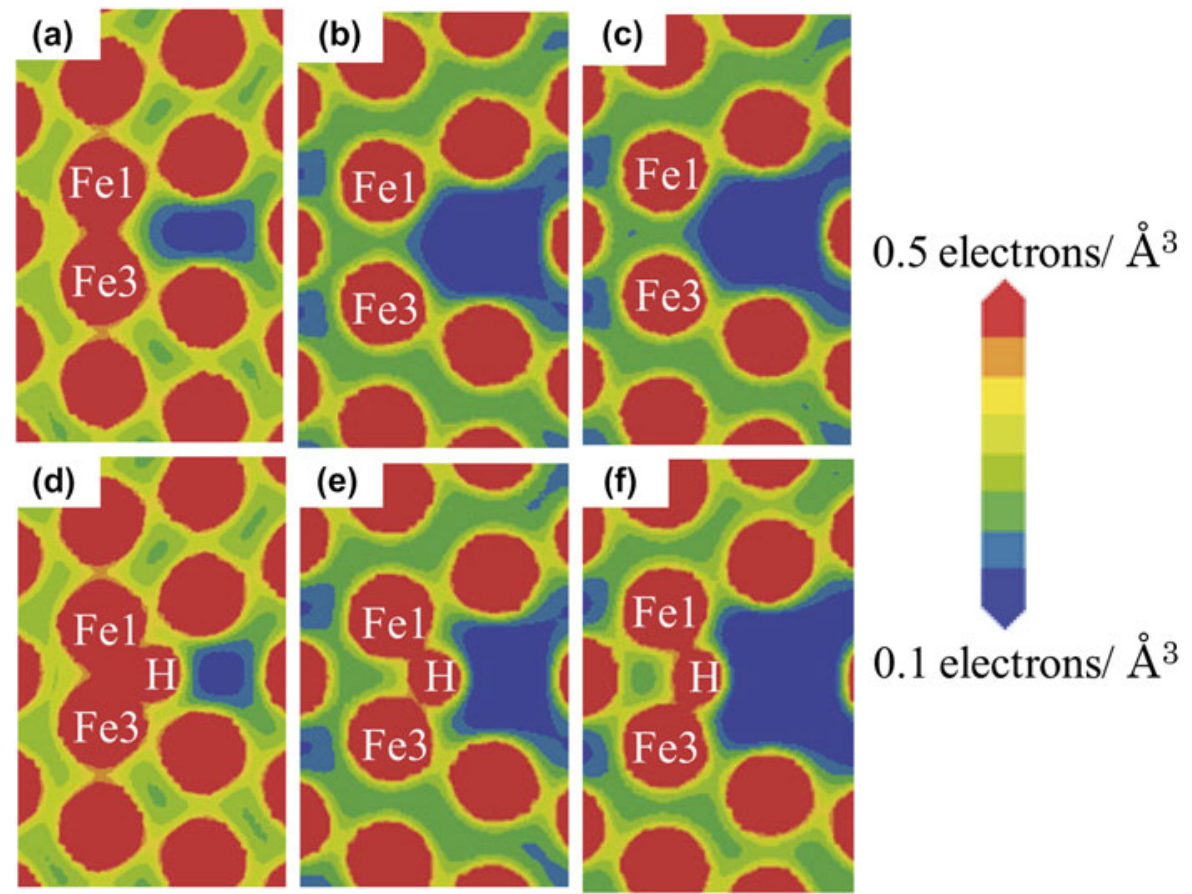

0.1 electrons $/ \AA^{3}$

FIG. 5. Charge-density distributions of (11̄0): (a), (b), and (c) show the charge-density distributions at $0 \%, 10 \%$, and $22 \%$, respectively, in the clean GB model, and (d), (e), and (f) show the charge-density distributions at $0 \%, 10 \%$, and $22 \%$, respectively, in the $\mathrm{H}$-segregated GB model. The $\mathrm{H}$ atom reinforces the $\mathrm{Fe} 1-\mathrm{Fe} 3$ bond in the $\mathrm{H}$-segregated GB model.

the GB embrittlement of Fe [33-36]. In the P-segregated $\mathrm{Fe} \mathrm{GB}$, because the Fe-P bond has intense covalent-like characteristics, the mobility of electrons is limited, resulting in premature breaking of the $\mathrm{Fe}-\mathrm{P}$ bond. ${ }^{17}$ In contrast, no premature breaking of the $\mathrm{Fe}-\mathrm{H}$ bond was found in the $\mathrm{H}$-segregated Fe GB. This suggests that the covalent-like characteristics of the $\mathrm{Fe}-\mathrm{H}$ bond are rather weak.

Figure 7 shows the charge-density distributions of [220] at $0 \%, 10 \%$, and $22 \%$. The charge densities between $\mathrm{Fe} 2$ and $\mathrm{Fe} 4(\mathrm{Fe} 5)$, and between $\mathrm{Fe} 4$ and $\mathrm{Fe} 5$, decreased during straining in the clean GB model, but the breaking of these bonds did not occur at $22 \%$. In contrast, the charge density between $\mathrm{Fe} 2$ and $\mathrm{Fe} 4(\mathrm{Fe} 5)$ in the H-segregated GB model decreased more during straining than it did in the clean $\mathrm{GB}$, and the $\mathrm{Fe} 2-\mathrm{Fe} 4(\mathrm{Fe} 5)$ bond was broken at $22 \%$. The breaking of the $\mathrm{Fe} 2-\mathrm{Fe} 4(\mathrm{Fe} 5)$ bond accelerated breaking of the $\mathrm{Fe} 4-\mathrm{Fe} 5$ bond, although the $\mathrm{Fe} 2$ atom bonded with other Fe atoms after breaking of the Fe2-Fe4 bond. Thus, breaking of the $\mathrm{Fe} 2-\mathrm{Fe} 4(\mathrm{Fe} 5)$ bond was enhanced in the $\mathrm{H}$-segregated GB model. This is due to larger decreases in the total occupation numbers of $\mathrm{Fe} 2$ and $\mathrm{Fe} 4(\mathrm{Fe} 5)$ in the $\mathrm{H}$-segregated GB model, as shown in Table I. The PDOSs of the $\mathrm{Fe} 4$ and $\mathrm{H}$ atoms at $0 \%, 10 \%$, and $20 \%$ in the H-segregated GB model are shown in Fig. 8. The hybridization peak of the $s$ electrons was found in the Fe4 and $\mathrm{H}$ atoms, as well as in the $\mathrm{Fe} 1$ and $\mathrm{H}$ atoms. However, the number of electrons related to hybridization in $\mathrm{Fe} 4$ was lower than that in $\mathrm{Fe}$, and was more reduced by strain.

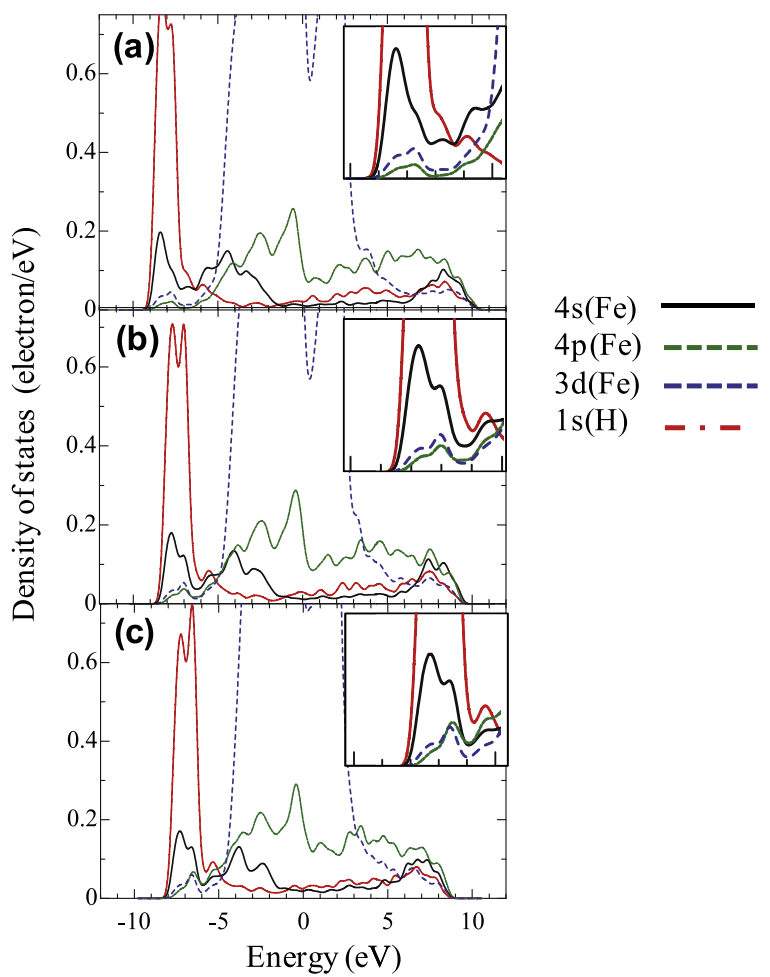

FIG. 6. PDOS of the $\mathrm{Fe} 1$ and $\mathrm{H}$ atoms in the $\mathrm{H}$-segregated GB model: (a) $0 \%$, (b) $10 \%$, and (c) $20 \%$. The Fermi level is defined as the zero of energy. Magnified figures of the PDOS in the range $-10 \mathrm{eV}$ to $-5 \mathrm{eV}$ are shown on the upper right. Hybridization peaks are observed at -9 to $-7 \mathrm{eV}$ in the $\mathrm{Fe} 1$ and $\mathrm{H}$ atoms. 


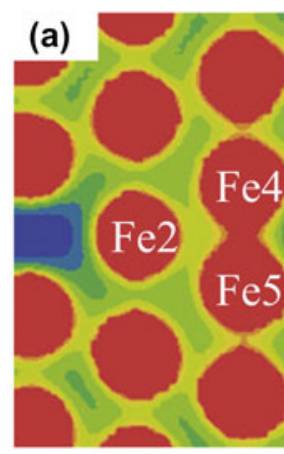

(d)

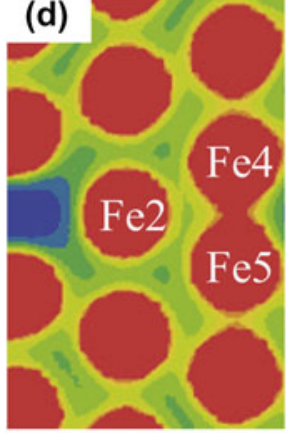

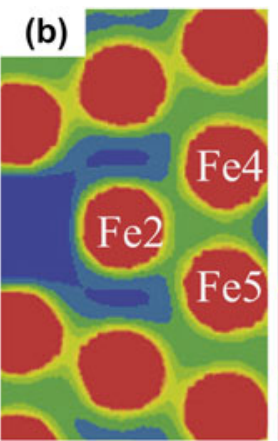

(e)

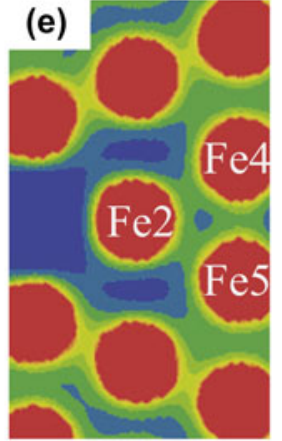

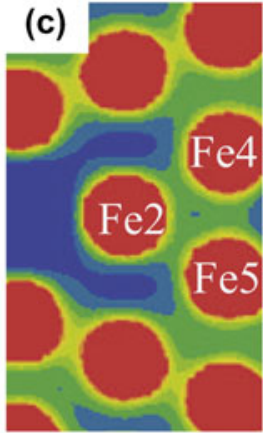

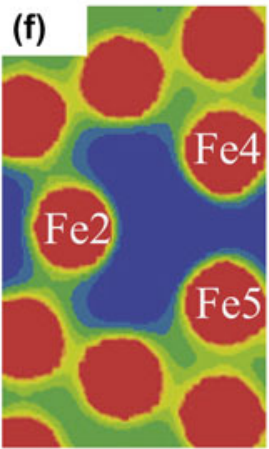

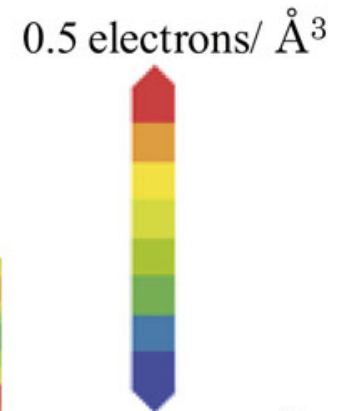

0.1 electrons/ $\AA^{3}$

FIG. 7. Charge-density distribution of $(2 \overline{2} 0)$ with strain: (a), (b), and (c) show the charge-density distributions at $0 \%, 10 \%$, and $22 \%$, respectively, in the clean GB model, and (d), (e), and (f) show the charge-density distributions at $0 \%, 10 \%$, and $22 \%$, respectively, in the $\mathrm{H}$-segregated GB model. Note that the charge density between $\mathrm{Fe} 2$ and $\mathrm{Fe} 4(\mathrm{Fe} 5)$ in the H-segregated GB model decreases more during straining than it does in the clean GB model.

Breaking of a metallic bond occurs through the transition state of a comparatively flat charge density at the bond critical point (BCP) ${ }^{37}$ Figure 9 shows the charge densities along the line, which is normal to the $\mathrm{Fe} 2-\mathrm{Fe} 4$ bond, from the $\mathrm{BCP}$ at $0 \%$ and $20 \%$ in the $\mathrm{H}$-segregated GB model. The charge-density curve at $20 \%$ was not flat at the BCP, as well as the charge-density curve at $0 \%$, suggesting that the $\mathrm{Fe} 2-\mathrm{Fe} 4$ bond had covalent-like characteristics. However, the breaking of the $\mathrm{Fe} 2-\mathrm{Fe} 4$ bond occurred readily, as shown in Fig. 3. It is therefore suggested that significant decreases in charge density around the $\mathrm{Fe} 2$ and $\mathrm{Fe} 4$ atoms, as a result of charge transfer, prevail over the covalent-like characteristics.

Lu et al. ${ }^{38}$ investigated the H-enhanced local plasticity mechanism of $\mathrm{Al}$ using shear test simulations, where the dislocation core structure is changed by the presence of $\mathrm{H}$ impurities, and the Peierls stress is reduced by more than an order of magnitude. Hence, it is interesting to investigate the effects of $\mathrm{H}$ on $\mathrm{GB}$ shearing behavior using shear test simulations. The variations in GB energy and atomic configurations of [1 $1 \overline{10}]$ during shearing are shown in Fig. 10. Cahn et al. ${ }^{39,40}$ showed that normal GB motion is coupled to tangential translation of grains and produces GB shearing, conversely, GB shearing induces normal GB motion. The coupling GB motion was found in both Fe GB models. Note that the coupling GB behavior did not depend on the presence of $\mathrm{H}$. Recently, Hyde et al. ${ }^{41}$ showed by molecular dynamics simulations that nucleation of GB dislocations is enhanced by $\mathrm{H}$ impurity. As

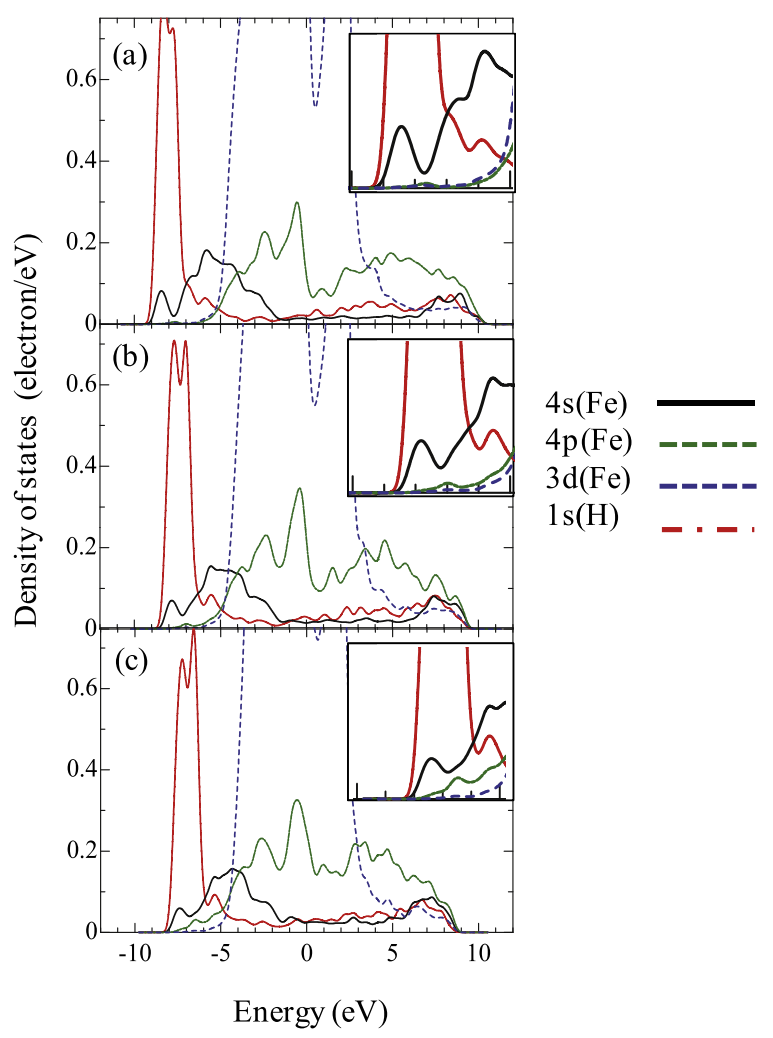

FIG. 8. PDOS of the Fe4 and $\mathrm{H}$ atoms in the $\mathrm{H}$-segregated $\mathrm{GB}$ model: (a) $0 \%$, (b) $10 \%$, and (c) $20 \%$. The Fermi level is defined as the zero of energy. The magnified figures of the PDOS in the range $-10 \mathrm{eV}$ to $-5 \mathrm{eV}$ are shown on the upper right. 
shown in Fig. 10, however, the enhanced GB shearing by $\mathrm{H}$ impurity was not found because events related to dislocations could not be treated in the first-principles calculations, and the variation in the GB energy for the $\mathrm{H}$-segregated GB model was almost the same as that for the clean GB model. This may be because of an offset of the strengthened $\mathrm{Fe}-\mathrm{H}$ bonds as a result of the covalentlike characteristics and the weakening of $\mathrm{Fe}-\mathrm{Fe}$ bonds caused by charge transfer.

Another important result in Fig. 10 is that periodicity in the energy-strain relation was found for the H-segregated GB model as well as for the clean GB model. Although the periodicity effect is entirely geometrical and depends on

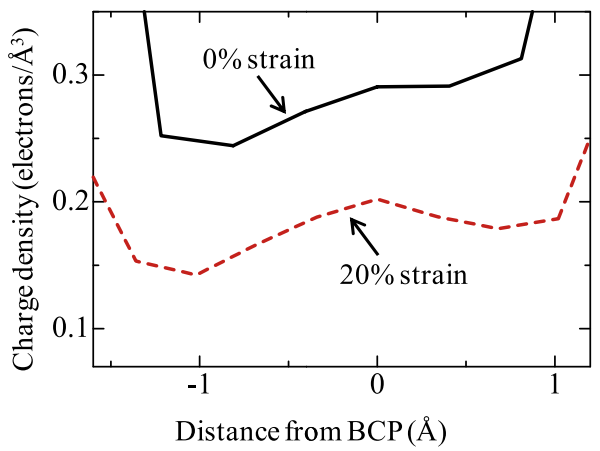

FIG. 9. Charge densities along the line, which is normal to the $\mathrm{Fe} 2-\mathrm{Fe} 4$ bond, from the $\mathrm{BCP}$ at $0 \%$ and $20 \%$ in the $\mathrm{H}$-segregated $\mathrm{GB}$ model. The charge-density curve at $20 \%$ is not flat at the BCP, as well as the chargedensity curve at $0 \%$. the GB structure, ${ }^{40}$ the periodicity is usually found in metallic bonding ${ }^{30,31}$ because it arises when the GB structure recovers its original form during shearing. The fact that the periodicity was found for the $\mathrm{H}$-segregated GB model indicates that the covalent-like characteristics of $\mathrm{Fe}-\mathrm{H}$ bonds played a minor role in GB shearing. Large variations in charge transfer during straining were found in GB fracture by tensile straining, which is responsible for the lower fracture energy for tensile deformation in the $\mathrm{H}$-segregated GB model, as shown in Fig. 2. However, bond-breaking and rebonding occur concurrently in GB shearing; therefore, large variations in charge transfer during straining are not found, resulting in minor difference in GB energy between the $\mathrm{H}$-segregated GB model and the clean GB model, as shown in Fig. 10. This explains why $\mathrm{H}$ segregation enhances GB embrittlement, but has little effect on GB shearing.

John et al. ${ }^{42}$ investigated effects of the loading mode on $\mathrm{H}$-induced embrittlement and they demonstrated that $\mathrm{Fe}$ alloy was more susceptible to $\mathrm{H}$-induced embrittlement in the tensile stress condition than in torsional stress condition, namely, the critical load for failure of the specimen with $\mathrm{H}$ charging was approximately one-sixth lower than that without $\mathrm{H}$ charging in the tensile stress condition, however, the difference between the specimens with and without $\mathrm{H}$ charging was only $14 \%$ in the torsional stress condition. In addition, they demonstrated from fractography that the intergranular fracture was induced by $\mathrm{H}$-charging in the tensile stress condition, but not in the

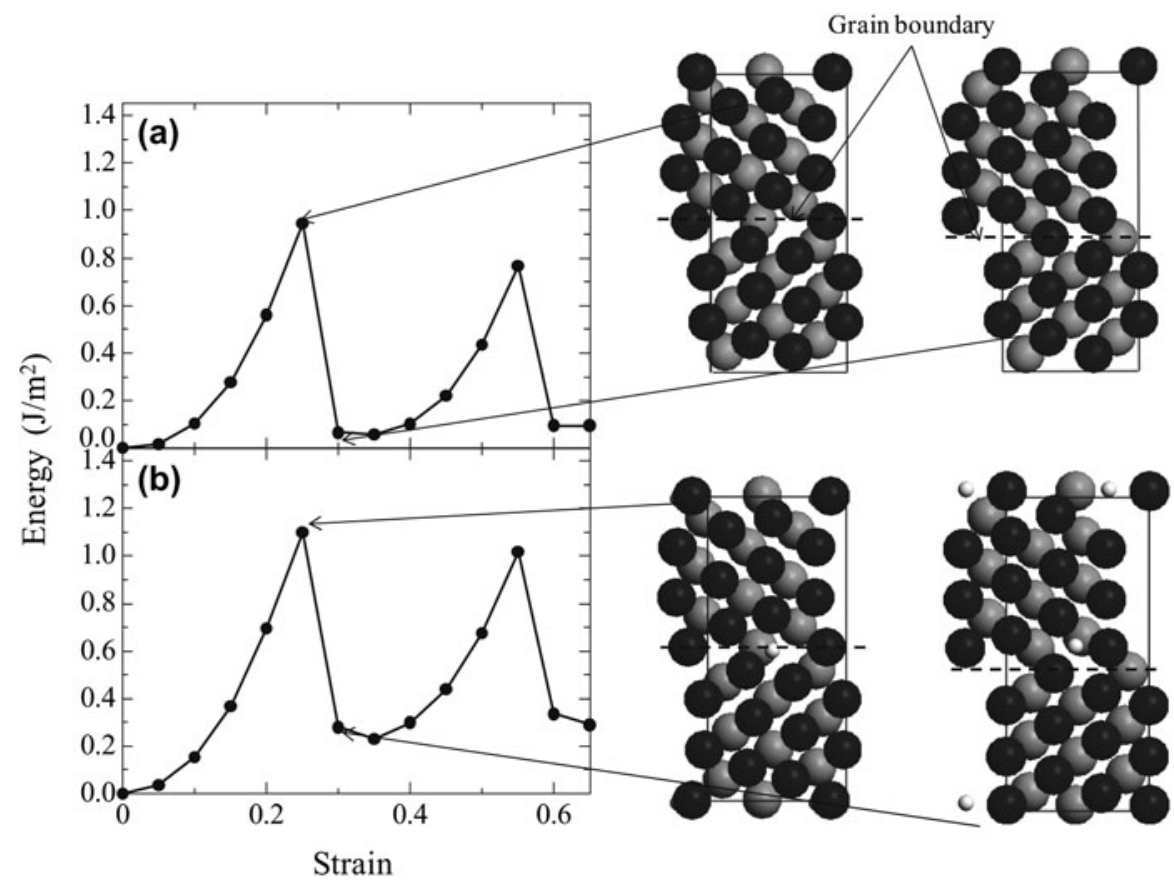

FIG. 10. Variations in GB energy as a function of strain and atomic configurations of (11̄0) during shearing from first-principles shear tests: (a) clean GB model and (b) H-segregated GB model. Periodicity in the energy-strain relation is found for the H-segregated GB model as well as for the clean GB model. 
torsion stress condition. The simulation results in the present work are in good agreement with these experimental results.

\section{SUMMARY}

We performed first-principles fully relaxed tensile and shear test simulations on $\Sigma 3(111) /[1 \overline{1} 0]$ tilt Fe GBs, with and without $\mathrm{H}$ segregation, to investigate the mechanisms of GB embrittlement enhanced by $\mathrm{H}$ segregation. Calculations of tensile tests revealed that $\mathrm{H}$ is a $\mathrm{GB}$ embrittler of $\mathrm{Fe}$, which agreed with estimates based on the Rice-Wang thermodynamics model. The Fe-H bond showed not only metallic bonding characteristics, but also covalent-like and ion-like characteristics. The covalent-like characteristics reinforced the $\mathrm{Fe}-\mathrm{Fe}$ bonds, while the ion-like characteristics weakened the $\mathrm{Fe}-\mathrm{Fe}$ bonds as a result of charge transfer. The variations in charge transfer with strain were enhanced by $\mathrm{H}$, and the effects of charge transfer prevailed over the effects of the covalent-like characteristics, resulting in GB embrittlement enhanced by $\mathrm{H}$ segregation. It was found from the shear test simulations that the effect of $\mathrm{H}$ on GB shearing was less than the effect of $\mathrm{H}$ on GB fracture. This is because bond-breaking and rebonding take place concurrently in GB shearing and the variations in charge transfer during shear straining are fewer than those during tensile straining.

\section{ACKNOWLEDGMENTS}

This work was supported by a Grant-in-Aid for JSPS Fellows (22.5568). Computation time was provided by the SuperComputer Laboratory, Institute for Chemical Research, Kyoto University.

\section{REFERENCES}

1. M. Nagumo: Hydrogen-related failure of steels-a new aspect. Mater. Sci. Technol. 20, 940 (2004).

2. P. Sofronis and I.M. Robertson: Transmission electron microscopy observations and micromechanical/continuum models for the effect of hydrogen on the mechanical behaviour of metals. Philos. Mag. A 82, 3405 (2002).

3. C.J. McMahon: Hydrogen-induced intergranular fracture of steels. Eng. Fract. Mech. 68, 773 (2001).

4. M. Tkacz: Thermodynamic properties of iron hydride. J. Alloys Compd. 330-332, 25 (2002).

5. J.R. Rice and J-S. Wang: Embrittlement of interfaces by solute segregation. Mater. Sci. Eng. A 107, 23 (1989).

6. L. Zhong, R. Wu, A.J. Freeman, and G.B. Olson: Charge transfer mechanism of hydrogen-induced intergranular embrittlement of iron. Phys. Rev. B 62, 13938 (2000).

7. G. Lu, D. Orlikowski, I. Park, O. Politano, and E. Kaxiras: Energetics of hydrogen impurities in aluminum and their effect on mechanical properties. Phys. Rev. B 65, 064102 (2002).

8. M. Yamaguchi, K. Ebihara, M. Itakura, T. Kadoyoshi, T. Suzuki, and H. Kaburaki: First-principles study on the grain boundary embrittlement of metals by solute segregation: Part II. metal (Fe, $\mathrm{Al}$, Cu)-hydrogen (H) systems. Metall. Mater. Trans. A 42, 330 (2011).

9. D. Farkas, R. Nogueira, M. Ruda, and B. Hyde: Atomistic simulations of the effects of segregated elements on grain-boundary fracture in body-centered-cubic Fe. Metall. Mater. Trans. A 36, 2067 (2005).

10. Y. Itsumi and D.E. Ellis: Electronic bonding characteristics of hydrogen in bcc iron: Part II. Grain boundaries. J. Mater. Res. 11, 2214 (1996).

11. S.B. Gesari, M.E. Pronsato, and A. Juan: The electronic structure and bonding of $\mathrm{H}$ pairs at $\Sigma=5 \mathrm{BCC}$ Fe grain boundary. Appl. Surf. Sci. 187, 207 (2002).

12. S. Gesari, B. Irigoyen, and A. Juan: Segregation of H, C and B to $\Sigma=5\left(\begin{array}{lll}0 & 1 & 3\end{array}\right) \alpha$-Fe grain boundary: A theoretical study. Appl. Surf. Sci. 253, 1939 (2006).

13. G-H. Lu, Y. Zhang, S. Deng, T. Wang, M. Kohyama, R. Yamamoto, F. Liu, K. Horikawa, and M. Kanno: Origin of intergranular embrittlement of $\mathrm{Al}$ alloys induced by $\mathrm{Na}$ and $\mathrm{Ca}$ segregation: Grain boundary weakening. Phys. Rev. B 73, 224115 (2006).

14. Y. Zhang, G-H. Lu, S. Deng, T. Wang, H. Xu, M. Kohyama, and R. Yamamoto: Weakening of an aluminum grain boundary induced by sulfur segregation: A first-principles computational tensile test. Phys. Rev. B 75, 174101 (2007).

15. Y. Zhang, G-H. Lu, M. Kohyama, and T. Wang: Investigating the effects of a $\mathrm{Ga}$ layer on an $\mathrm{Al}$ grain boundary by a first-principles computational tensile test. Model. Simul. Mater. Sci. Eng. 17, 015003 (2009)

16. M. Yuasa and M. Mabuchi: Effects of segregated $\mathrm{Cu}$ on a $\mathrm{Fe}$ grain boundary by first-principles tensile tests. J. Phys. Condens. Matter 22, 505705 (2010).

17. M. Yuasa and M. Mabuchi: Bond mobility mechanism in grain boundary embrittlement: First-principles tensile tests of Fe with a P-segregated $\Sigma 3$ grain boundary. Phys. Rev. B 82, 094108 (2010).

18. C.L. Briant and R.P. Messmer: Electronic effects of sulfur in nickel a model for grain boundary embrittlement. Philos. Mag. B 42, 569 (1980).

19. R.P. Messmer and C.L. Briant: The role of chemical bonding in grain boundary embrittlement. Acta Metall. 30, 457 (1982).

20. R. Haydock: The mobility of bonds at metal surfaces (heterogeneous catalysis) J. Phys. C: Solid State Phys. 14, 3807 (1981)

21. L. Goodwin, R.J. Needs, and V. Heine: Effect of impurity bonding on grain-boundary embrittlement. Phys. Rev. Lett. 60, 2050 (1988).

22. L. Goodwin, R.J. Needs, and V. Heine: A pseudopotential total energy study of impurity-promoted intergranular embrittlement. J. Phys. Condens. Matter 2, 351 (1990).

23. M.C. Payne, M.P. Teter, D.C. Allan, T.A. Arias, and J.D. Joannopoulos: Iterative minimization techniques for ab initio total-energy calculations: Molecular dynamics and conjugate gradients. Rev. Mod. Phys. 64, 1045 (1992).

24. P. Hohenberg and W. Kohn: Inhomogeneous electron gas. Phys. Rev. 136, B864 (1964).

25. W. Kohn and L. Sham: Self-consistent equations including exchange and correlation effects. Phys. Rev. 140, A1133 (1965).

26. J.P. Perdew, K. Burke, and M. Ernzerhof: Generalized gradient approximation made simple. Phys. Rev. Lett. 77, 3865 (1996).

27. D. Vanderbilt: Soft self-consistent pseudopotentials in a generalized eigenvalue formalism. Phys. Rev. B 41, 7892 (1990).

28. T.H. Fischer and J. Almlof: General methods for geometry and wave function optimization. Phys. Rev. Chem. 96, 9768 (1992).

29. H.J. Monkhorst and J.D. Pack: Special points for Brillouin-zone integrations. Phys. Rev. B 13, 5188 (1976)

30. C. Molteni, G.P. Francis, M.C. Payne, and V. Heine: First-principles simulation of grain boundary sliding. Phys. Rev. Lett. 76, 1284 (1996).

31. C. Molteni, N. Marzari, M.C. Payne, and V. Heine: Sliding mechanisms in aluminum grain boundaries. Phys. Rev. Lett. 79, 869 (1997). 
32. M. Yamaguchi: First-principles study on the grain boundary embrittlement of metals by solute segregation: Part I. iron $(\mathrm{Fe})$-solute (B, C, P, and S) systems. Metall. Mater. Trans. A 42, 319 (2011).

33. R. Wu, A.J. Freeman, and G.B. Olson: First-principles determination of the effects of phosphorus and boron on iron grain boundary cohesion. Science 265, 376 (1994).

34. R. Wu, A.J. Freeman, and G.B. Olson: Nature of phosphorus embrittlement of the $\mathrm{Fe} \Sigma 3[1 \overline{1} 0](111)$ grain boundary. Phys. Rev. B 50, 75 (1994).

35. M. Yamaguchi, Y. Nishiyama, and H. Kaburaki: Decohesion of iron grain boundaries by sulfur or phosphorous segregation: Firstprinciples calculations. Phys. Rev. B 76, 035418 (2007).

36. Y-Q. Fen and C-Y. Wang: Electronic effects of nitrogen and phosphorus on iron grain boundary cohesion. Comput. Mater. Sci. 20, 48 (2001).
37. M.E. Eberhart, D.P. Clougherty, and J.M. Maclaren: A theoretical investigation of the mechanisms of fracture in metals and alloys. Am. Chem. Soc. 115, 5762 (1993).

38. G. Lu, Q. Zhang, N. Kioussis, and E. Kaxiras: Hydrogen-enhanced local plasticity in aluminum: An ab initio study. Phys. Rev. Lett. 87, 095501 (2001).

39. J.W. Cahn, Y. Mishin, and A. Suzuki: Duality of dislocation content of grain boundaries. Philos. Mag. 86, 3965 (2006).

40. J.W. Cahn, Y. Mishin, and A. Suzuki: Coupling grain boundary motion to shear deformation. Acta Mater. 54, 4953 (2006).

41. B. Hyde, D. Farkas, and M.J. Caturla: Atomistic sliding mechanisms of the $\Sigma=5$ symmetric tilt grain boundary in bcc iron Philos. Mag. 85, 3795 (2005).

42. C.S.T. John and W.W. Gerberich: The effect of loading mode on hydrogen embrittlement. Metall. Trans. 4, 589 (1973). 